\title{
Hybrid rockfall barrier - new design methodology based on the Colorado full-scale test experience
}

\author{
M Cerro Maccaferri Asia, Malaysia \\ G Giacchetti Officine Maccaferri, Italy \\ M Lelli Maccaferri Asia, Malaysia
}

A Grimod France Maccaferri, France

A Arul Maccaferri Asia, Malaysia

\begin{abstract}
Hybrid rockfall barriers combine the energy absorption capabilities of a dynamic rockfall barrier with the reduced-maintenance advantages of drapery mesh. The aim of this innovative design is not to capture and stop the falling rocks, as the barriers tested according to ETAG 027 (EOTA 2008), but to contain the bounce of the rock and to drive it down the slope beneath the mesh draped down the slope face.

Although this type of rockfall structure has already been applied worldwide, there is still a lack of knowledge in the design methodology. The purpose of this paper is to present a simplified model to design hybrid barriers based on the field experiences and research carried out by the Colorado Department of Transportation, "Colorado's full-scale field testing of rockfall attenuator system" (Arndt et al. 2009), giving designers a tool for sizing both the structure in elevation that the interception structure (net) and assessing the forces transmitted to the foundations.
\end{abstract}

\section{Introduction}

Nowadays flexible barriers (Figure 1) have become standard practice worldwide, further to their technological development and the test procedures, which allowed a full analysis and check on their performance and behaviour at all operational European Organisation for Technical Approval (ETAG) tests procedure (EOTA 2008).

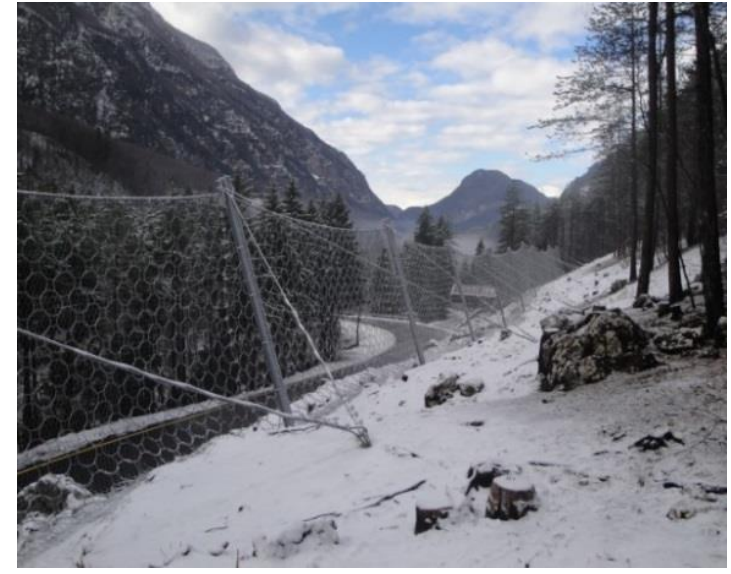

Figure $12,000 \mathrm{~kJ}$ flexible rockfall barrier — Val Raccolana, Italy

These types of barriers are designed to absorb energy through deformation of the fence (rings net, ropes panel, double twist mesh etc.) and braking elements. Posts and brake cables are secured to the ground using anchors. 
Regular inspections and ongoing maintenance is required to remove rockfall debris, and replace damaged elements.

Historically it was observed that flexible barriers were deemed unsuitable to protect facilities intercepting drainages, chutes, and swales generating rockfalls with a high frequency due to the high cost of maintenance. Or, where it is difficult to reach the barrier after the installation (difficult topography), (Duffy 2007).

The hybrid barrier, a modified standard flexible barrier, aims to address these issues and to present a more cost effective solution (Figure 2).

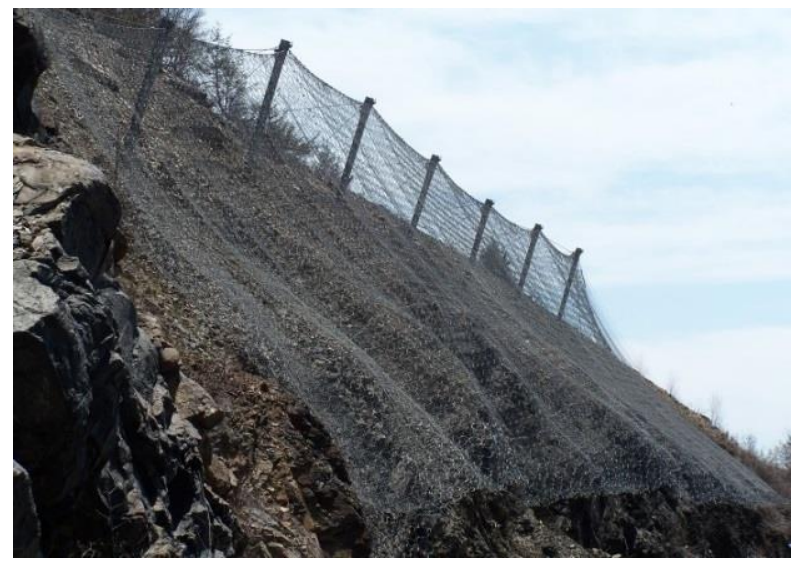

Figure 2 3,000 kJ hybrid barrier - Route 248, Lehigh Gap, Lehigh Township, Pennsylvania, United States

A hybrid barrier is a passive rockfall protection system consisting of a flexible, woven wire, ring net or cable fabric suspended from a horizontal top support cable raised off a slope surface by posts, or suspended by anchors across a chute. Usually internal, side and bottom anchoring of the fabric is limited, or eliminated, to allow maximum flexibility of the system and attenuation, and/or containment of rockfalls at the base of the system. Thus, hybrid barriers address rockfall source areas, both underneath and upslope of the installation, and control the rocks descent under the fabric, combining the performance of standard unsecured draperies and flexible rockfall fences. Consequently, they protect more slope area with less coverage, then would be required with a full drapery. Also, installation can occur higher upslope, without increasing maintenance costs and can capture higher energies blocks with a less robust fence infrastructure (Badger et al. 2008; Smerekanicz et al. 2008; Badger 2007).

\section{Attenuator and hybrid barrier}

Literature sometimes refers to hybrid barrier and attenuators (Figures 2 and 3), but does not differentiate between them; for instance, Turner et al. 2013 defines hybrid drapery such types of structures.

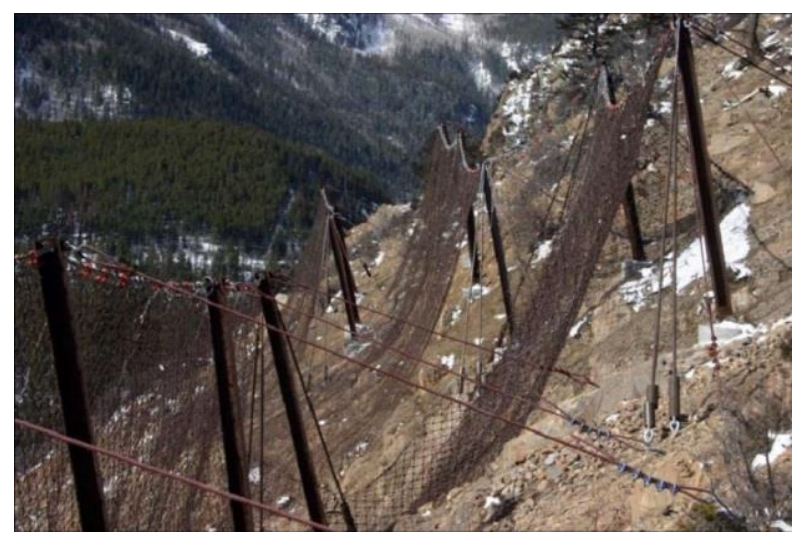

Figure 3 View of prototype attenuator system installed above Georgetown Incline (Arndt et al. 2009)

In this section, the author is proposing a distinction between these two types of structure. 
- The attenuators were largely tested by the Colorado Department of Transportation (Arndt et al. 2009). These structures are not intended to stop rock block, but, instead to reduce the kinetic energy associated with rockfall debris and to allow the rock blocks to continue down the slope for collection at the base of the slope. Whereas these structures would be installed in series, the higher the number of barriers installed is, the greater the control achieved is on the rockfall events and the smaller the area is where the resulting debris accumulates, at the base of the slope (Arndt et al.2009), (see Figure 4).

Tested structures are able to dissipate a maximum kinetic energy of $500 \mathrm{~kJ}$. Usually these types of barriers are positioned along the slope far from the facilities and their draped tails have a limited length (between 3 and $10 \mathrm{~m}$ ), (see Figure 5).

- The hybrid barriers are intended to dissipate the biggest part of the rockfall energy (up to 90\%), and to drive the rock, with limited residual energy, down the slope. Thus, the system does not require an alignment of multiple barriers.

The hybrid barriers are located near the deposition area, e.g. ditch, and their draped tails will reach approximately the collection area, in order to drive the rocks through and to act as simple drapery net.

\section{Typical Hybrid Mitigation Scheme}

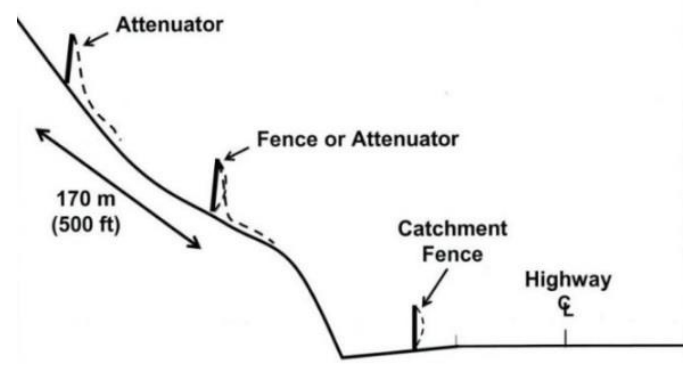

Figure 4 Conceptual diagram showing installation of the attenuator sequence (Arndt et al. 2009)

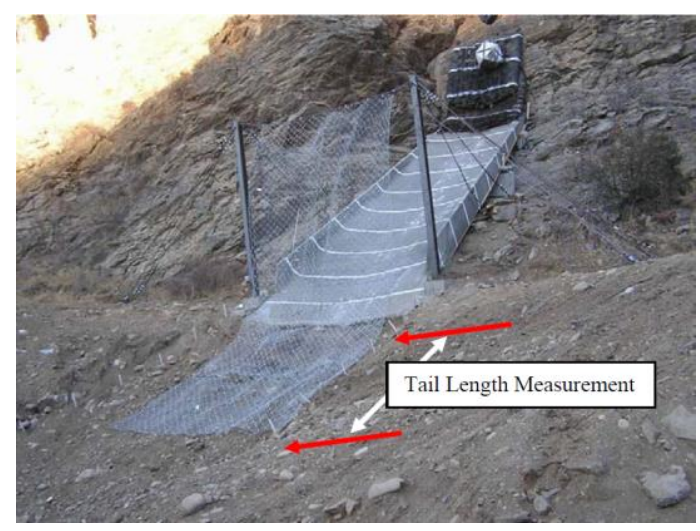

Figure 5 Measurement of tail length for net panel in contact with the ground (Arndt et al. 2009)

Although the application of the systems is different, the behaviour under a rockfall impact of the structures is similar, as shown during the full scale tests carried out by the Colorado Department of Transportation (CDOT), (Arndt et al. 2009), and Sussadelli et al. (2007). In fact both systems:

- Expose the upper portion of the drapery to impact orthogonal to the plane of the mesh.

- Dissipate the rock energy principally by the deformation of the draped tail.

- Channelise the rockfall under the drapery.

- Confine the trajectory within the plane of the mesh. 
Based on these observations, the following sections proposes an analytic calculation approach for the design of hybrid barriers, starting with the results obtained by the Transportation Research Circular E-C141 (Arndt et al. 2009) on the attenuator system, and taking into account the structural differences between the systems.

\section{Hybrid barrier components}

The typical components of a hybrid barrier are (Figure 6):

- Main interception structure: a rockfall mesh, generally ring nets panels or woven steel wire rope panels, held up by the upper longitudinal ropes. Its purpose is to withstand the direct impact of the mass, deforming elastically and/or plastically, and transmitting the stress to the connection components, the support structure (longitudinal cables and posts) and the foundations.

- Secondary interception structure: generally double twist mesh held up by the upper longitudinal ropes and connected to the main interception structure. Its purpose is to hold the smaller debris and rocks that could pass through the main interception structure.

- Upper longitudinal ropes: steel ropes that longitudinally run in the upper part of the hybrid barrier. These ropes are able to transfer the forces, developed by the event, from the interception structure to the lateral anchors and posts.

- Upslope bracing ropes: connect the head of the posts to the upslope anchors.

- Energy dissipater devices (brakes): are inserted into the longitudinal ropes and/or upslope bracing cables in order to dissipate the impact energy of the rockfall, by deformation. The deformation of the brakes allows the extension of the ropes and, consequently, the forces acting on the anchors and structural components of the barrier (posts, interception structure etc.) to decrease (Figure 7).

- Posts: constituted by steel beams (usually High Energy Absorption net (HEA) or tubular profiles). They are connected, at the top, to the upper longitudinal cable and bracing cables; the lower part of the post is usually connected to the base plate, with a pin that allows rotation.

- Post anchoring system: constituted of a small concrete plinth, with a micropile and/or rod steel bars.

- Lateral anchors and upslope anchors: are composed usually of a double-leg flexible rope. They are installed in a drilled hole and fully grouted. They transfer the forces from the barrier to the ground.
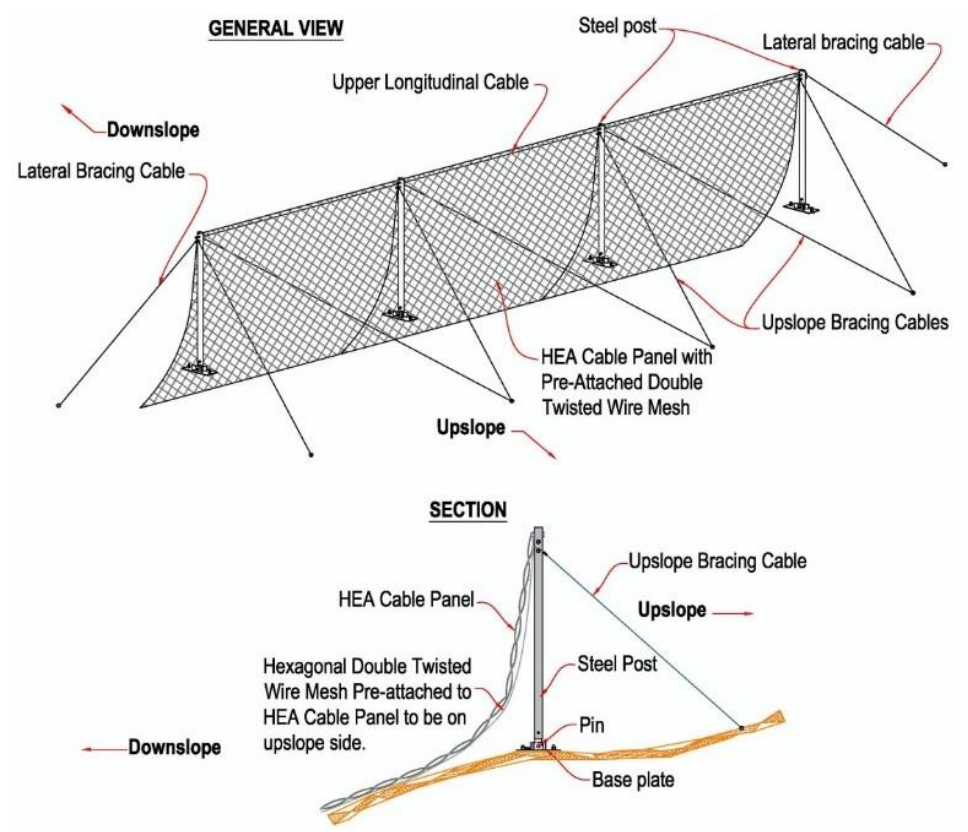

Figure 6 Hybrid barrier main components 


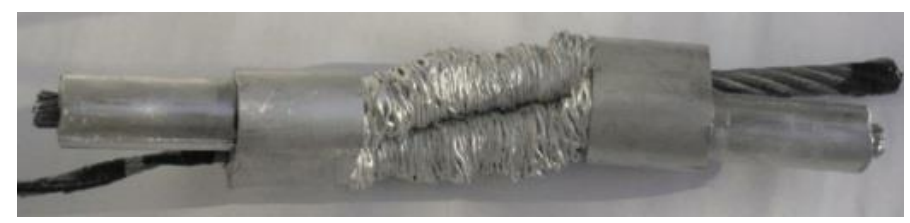

Figure 7 Example of energy dissipater device (brake). The deformation of the device absorbs the impact energy from the rockfall

\section{$4 \quad$ How a hybrid barrier works}

The setup of the barrier as described in Section 3, allows the structure to work as a flexible rockfall barrier, and as a drapery curtain at the same time, e.g. hybrid behaviour. The system operates at three different stages (Figure 8), namely:

- Zone A - Interception: The barrier is designed to first catch the falling rock, through rolling, bouncing or sliding, as a standard flexible rockfall barrier. The biggest dissipation of energy, e.g. kinematic, will occur at this stage due to the elasto-plastic deformation of the draped net (main interception structure), to the friction between the rock and the interception structure, and to the plastic deformation of the energy dissipater devices.

- Zone B - Transition: The draped fence tail of the barrier drives rocks and debris toward the toe of the slope, slowing the speed down and, therefore, reducing the energy. The draped fence hangs on the upper longitudinal cable. The heavier the main interception structure, and the longer the length of the draped tail, the greater the energy dissipated during this transition part of the system.

- Basically the energy dissipates within zone B of the barrier is due to the friction between the draped net and the slope surface.

- Zone C - Funnel out: The draped fence tail is open at its bottom to allow the rocks/debris to be free to roll out. The speed and the corresponding energy of the debris through this area will be significantly reduced due to the dissipation that has occurred through Zones A and B. However, it is crucial to design a catching structure in this zone (ditch, flexible fence, embankment etc.), to collect the rocks and debris, in order to avoid any rocks continuing downslope (Figure 9).

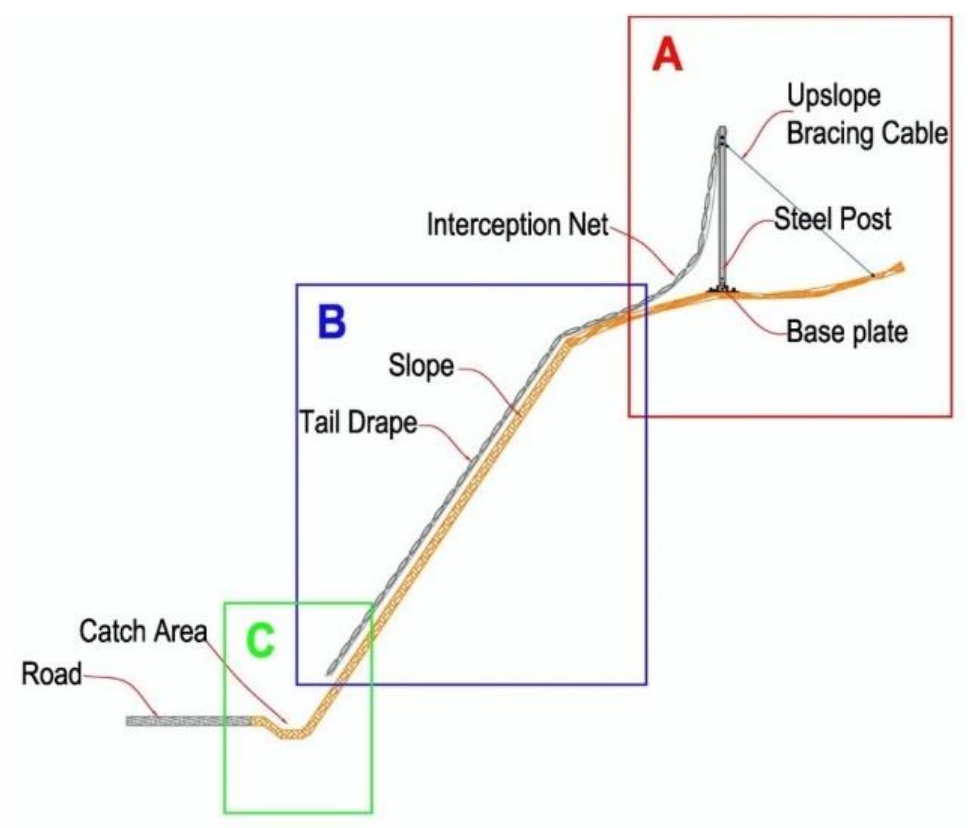

Figure 8 Hybrid barrier main zone: (a) rock interception and energy dissipation; (b) rock bounce control and energy dissipation; and, (c) collecting area (ditch, embankment, flexible rockfall barrier) 


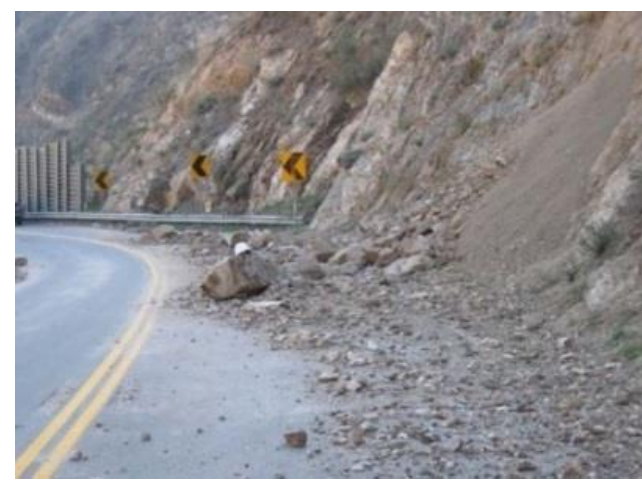

(a)

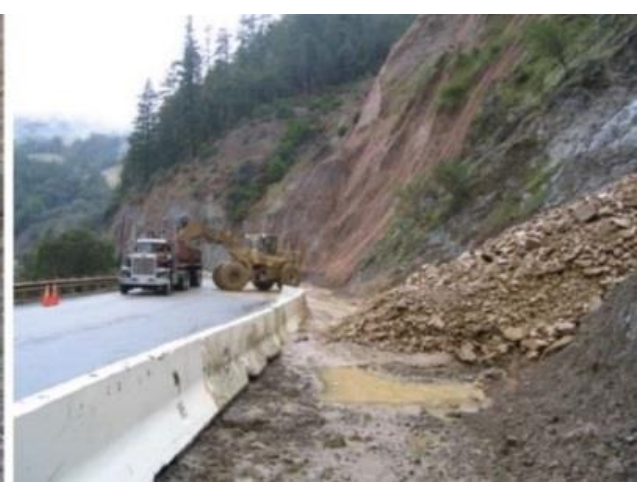

(b)

Figure 9 Slope protected with a hybrid barrier: (a) the toe of the slope is not protected, i.e. the rocks roll into the middle of the road; and, (b) the toe of the slope is protected with a concrete barrier with a height of $1.2 \mathrm{~m}$, therefore, the rocks are caught behind the barrier

\section{$5 \quad$ How to design a hybrid barrier}

This section presents an analytic calculation methodology that takes into account the numerous observations of hybrid barrier impacts, worldwide, and the study undertaken by Arndt et al. (2009) to improve understanding of the performance and behaviour of several of the currently available types of net (single twist, double twist, ring, cable etc.).

A series of steps are proposed that should be taken into account during the design of hybrid barriers, in particular:

- Evaluation of the input data necessary to design the hybrid rockfall barrier.

- Evaluation of the dynamic impact on the barrier and selection of the barrier.

- Evaluation of the static load on the barrier.

\section{$5.1 \quad$ Input data}

\subsubsection{Energy and barrier position}

The basic input data should include the number of unstable rocks, and the dimension of such, as well as the potential trajectories of the unstable blocks and their energy. Particularly:

- Geological and topographic surveys are required, to characterise any unstable area. The first step is to identify the number, and the dimension, of the potential unstable blocks and to identify the substrate conditions present along the slope. Consequently, this allows definition of the restitution coefficients and surface friction parameters along the slope surface and to define the geometry of the catchment area underneath.

- The study of the trajectories can be done with any professional software available on the market (Figure 10), in order to define the energy, velocity, bounce heights, and the end point of the falling masses. The most useful software allows the user to check each of these parameters at any point along the slope.

- Back analysis of actual rockfall data, and the results of such, shall be considered compulsory in order to validate the rockfall model. 


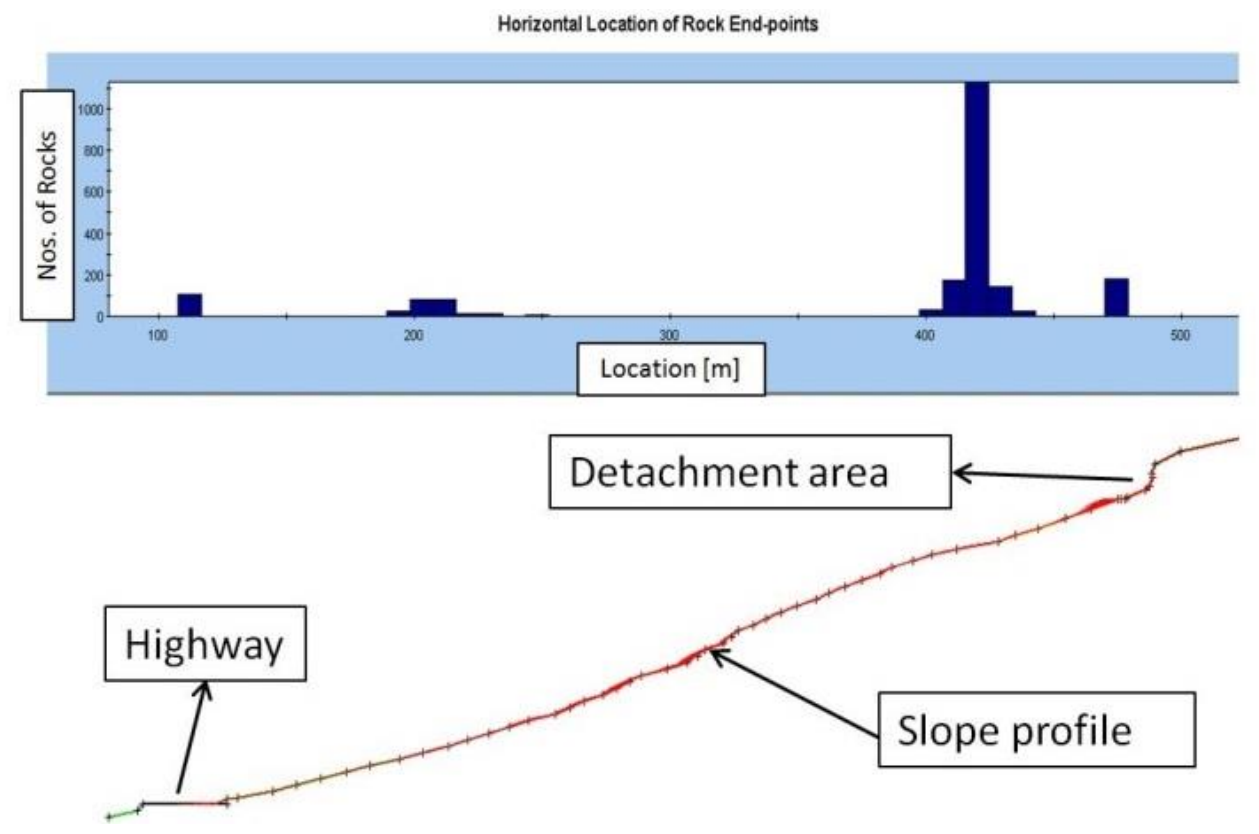

Figure 10 Example of a rockfall simulation with commercial software

Once all the data are collected, the model of the rockfall trajectories can be used to select the optimal location for the rockfall barriers, and the dynamic demands that will impose on the barrier, can be determined.

Figure 10 shows a rockfall simulation performed with commercial software, which executes a calculation according to the lumped mass analysis approach. For a lumped mass model, the normal coefficient of restitution, $R_{n}$ (parameter that depends on the material property of the soil, and ranges between 0.1 to 0.2 ), and tangential coefficient of friction resistance, $R_{t}$, (experimental parameter that depends on the slope material and the vegetation, and ranges between 0.5 to 1.0), must be defined. Moreover, the rock is considered as dimensionless point mass. Nowadays, new methods have been implemented to offer a more realistic behaviour of the falling blocks. For example, the rigid body impact mechanics model introduces the effect of the size and shape of the rock and its interaction with the slope. It uses the soil material parameters $R_{n}, R_{t}$, dynamic friction coefficient, $\mu$ (tangent of the friction angle, obtained with experimental data), and the rolling friction (Chai et al. 2013).

As shown in Figure 10, from this calculation it is possible to define the statistical distribution of the end-points onsite. For instance, in this specific case, $15 \%$ of the blocks stopped in the first $20 \mathrm{~m}$ from the detachment area, $60 \%$ in the next $30-40 \mathrm{~m}, 20 \%$ in the following $150-200 \mathrm{~m}$, and only 10 blocks (approximately 5\%) reached the highway downslope. Moreover, with commercial software, it is possible to define energy, rock velocities, and bounce heights. These parameters will be used in the following sections to define the structure of the barrier.

\subsubsection{Slope geometry data}

To properly design a hybrid barrier, it is necessary to know the static loads, which will act on the barrier, and the dynamic loads generated by the impact of any rockfalls. In particular, we have to know:

- The weight of the main and secondary interception structure (i.e. weight of the ring net plus double twist mesh) and the friction angle between the net and the slope.

As reported by Muhunthan et al. (2005), where the slope is planar and the surface is smooth, or when the slope is steep, minimal interface friction may be present. In these cases, the mobilised force on the system is carried largely by the structure (posts and anchors). Where slopes are highly irregular and the surfaces are rough or have abrupt protrusions, very high interface friction 
may be present. In these cases, very little to no mobilised force may be imparted to the main structure.

Typical values of the friction angle between the mesh and slope are:

$\circ$ Rough slope: $60^{\circ}$.

○ Undulating slope: $36-59^{\circ}$.

- Planar slope: $25-35^{\circ}$.

- Volume of the possible debris accumulation as results of entrapment of the loose materials by the net and the friction angle between mesh and debris.

- Loads due to snow and ice accumulation on the net, if applicable.

It is important to highlight that slopes steeper than about $70^{\circ}$ typically do not accumulate debris because the majority of the mesh usually hangs free of the slope and, therefore, only a minor component of mesh weight acts against the slope. Mesh systems on flatter slopes exert a greater weight component and, hence, have a greater tendency to accumulate debris. In addition, slopes flatter than about $60^{\circ}$ may also be at risk for accumulating snow, which can exert large loads on the barrier. Even so, increased mesh weight and the degree of slope contact can also have the positive effect of arresting or reducing erosion and the movement of debris behind the mesh (Muhunthan et al. 2005).

\subsection{Dynamic design}

Within Zone A (Figure 8) the hybrid barrier is impacted by the rocks and it dissipates/absorbs the energy. The energy of the impacts is calculated according the Section 5.1.1 through commercial software or through a back analysis approach. Complete explanation of the rockfall analysis can be found in other literature (e.g. Turner et al. 2013).

This energy absorption occurs through the transformation of kinetic energy to mechanical work (deformations of the overall component of the hybrid barrier: energy dissipater devices, net, longitudinal rope etc.). Therefore, to confirm the rockfall protection efficiency, the following equation corresponding to the equilibrium conditions has to be satisfied:

$$
E_{c}=L_{d}
$$

where:

$E_{c}=$ is the kinetic energy of the rockfall.

$L_{d}=$ is the deformation work (elastic and plastic) of a rockfall barrier due to the force of the rock that hits the barrier.

In conclusion, these types of structures, both flexible rockfall barriers according to ETAG and hybrid barriers, rely on the deformation of each of their components to dissipate the energy. Greater deformations/displacements result in greater kinetic energy dissipation.

To evaluate the energy dissipation of a hybrid barrier it is possible to do a comparison with the well-known flexible barriers.

The kinetic energy that the barrier has to dissipate and the mass of the impacting rock are known (see Section 5.1.1), so it is possible to evaluate the force acting immediately after the impact of the rock on the barrier. The theorem used to calculate this force is the impulse theorem (Newton's 2nd law equation):

$$
E_{c}=1 / 2 m v^{2}
$$

where:

$m=$ is the mass of the rock.

$v=$ is the impact velocity of the rock. 
Both the parameters, previously reported, are known from the rockfall analysis and in situ evaluations.

To calculate the force (F) that will act on the barrier, it is possible to apply the Newton's 2nd law equation:

$$
\mathrm{F} \Delta \mathrm{t}=\mathrm{m} v
$$

And it is possible to write:

$$
\mathrm{F}=\mathrm{m} v / \Delta \mathrm{t}
$$

where: $\Delta t$ is the impact period, that is the time necessary for the barrier to 'stop' a rock with a mass $m$ and a velocity $v$.

For the standard flexible barrier this value could be extracted from the ETAG test and a typical value is about $0.25 \mathrm{sec}$.

The important consideration that it is possible to assert from the field observations of the hybrid barriers, and from the CDOT document, is that the impact period of this type of structure is longer compared with a standard flexible barrier according to ETAG. In particular, the full scale test ran by the CDOT shows that the time the tail remains elevated in the air ranges between 0.5 to 1.5 second depending on tail length and mesh density (see Figure 11). The mesh density is defined as the mass per unit area of the net draped $\left(\mathrm{kg} / \mathrm{m}^{2}\right)$.

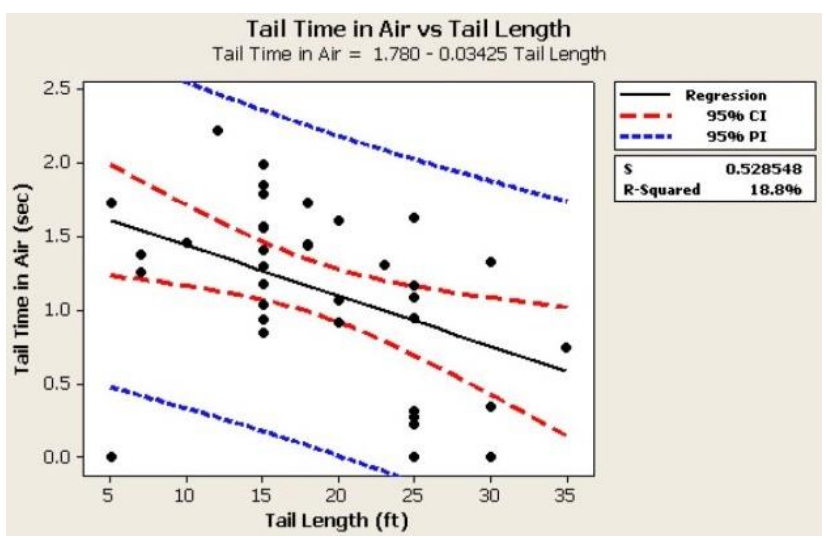

(a)

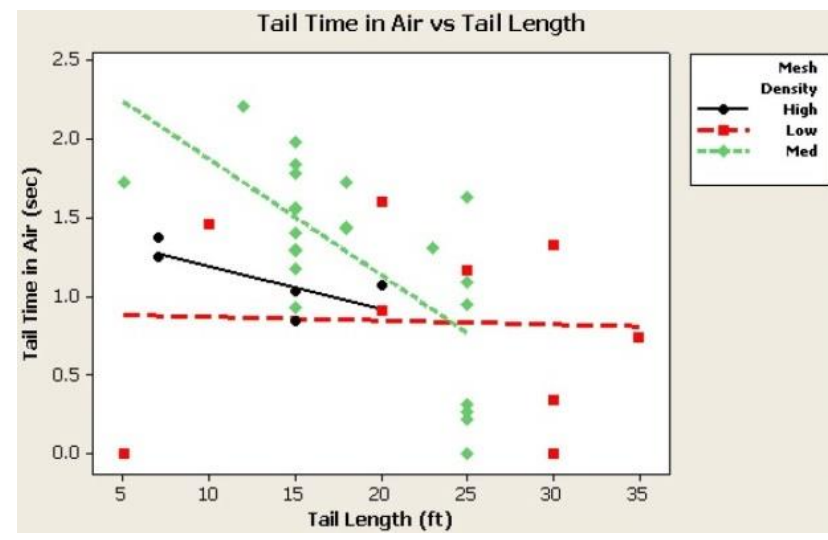

(b)

Figure 11 Graphs showing the time the tail remains elevated in the air (Arndt et al. 2009): (a) tail time in the air versus tail with subsets showing size of rock test; and, (b) tail time in the air versus tail with subsets is showing size mesh densities (Arndt et al. 2009)

With references to Figure 11 it is possible to observe that longer or heavier is the draped tail shorter is the time that the draped tail stays in air.

To be safe we can assume that:

$$
\Delta \mathrm{t}_{\text {hybrid barrier }}=2 \Delta \mathrm{t}_{\text {flexible barrier }}
$$

Therefore, by substituting these values in the Equation (4), considering constant mass and impact velocity for both hybrid and flexible barrier, it is possible to achieve the equivalence:

$$
F_{\text {Hybrid barrier }}=\frac{F_{\text {Flexible barrier }}}{2}
$$

In conclusion, it is possible to assert that for fixed impact energy $E_{c}$, the forces, which will act on each component of the hybrid barriers, will always be lower than a flexible barrier.

However, it is theoretically impossible to calculate the exact loads that will act on each component of the hybrid barrier during the rockfall impact.

For these reasons, the authors' suggest using the same type of structures, i.e. posts, ropes, interception structure, foundations etc., and configuration used for the ETAG certified flexible barriers, and apply this to hybrid barriers. 
Using this approach the designer can ensure a higher safety factor because he is using a structure that is designed to withstand forces which are almost double as compared to the real forces acting on the hybrid fences in the field (see Equation (6)).

\subsection{Static design}

Once the barrier type has been selected (see Section 5.2) it is necessary to design the structure to be able to withstand static loads of the accumulated debris under the tail of the draped net, snow and mesh weight.

It is essential to highlight that the static loads acting on the structure are usually lower than the dynamic loads acting during the rockfall impact. Static loads could be greater than dynamic loads for barriers with a very long tail (i.e. above $50 \mathrm{~m}$ ), installed on smooth and steep slopes (above $70^{\circ}$ inclination) and a huge quantities of debris is trapped under the draped net. This condition is a very unlikely event to occur. Generally slopes steeper than $70^{\circ}$ do not accumulate debris since majority of the mesh hangs free along the slope.

In conclusion, this analysis is necessary to:

- Check if the tensile strength of the principal interception structure (ring net, woven rope panel etc.) is able to withstand the static loads generated.

- Choose the number of upper longitudinal ropes required, and their sag, to avoid the static loads activating the energy dissipater device.

The first point is usually satisfied as the types of interception structures chosen to withstand the dynamic loads (Section 5.2) have high tensile resistance (e.g. ring net).

To analyse the second point it is necessary to know the tensile-deformation behaviour of the brakes; in fact, the activation force of the dissipater device is required to carry out this calculation.

Section 5.3.1 explains the calculation method to analyse these two points.

\subsubsection{Static loads}

The static loads acting on the hybrid barrier are calculated according to Muhunthan et al. (2005), (Figure 12).
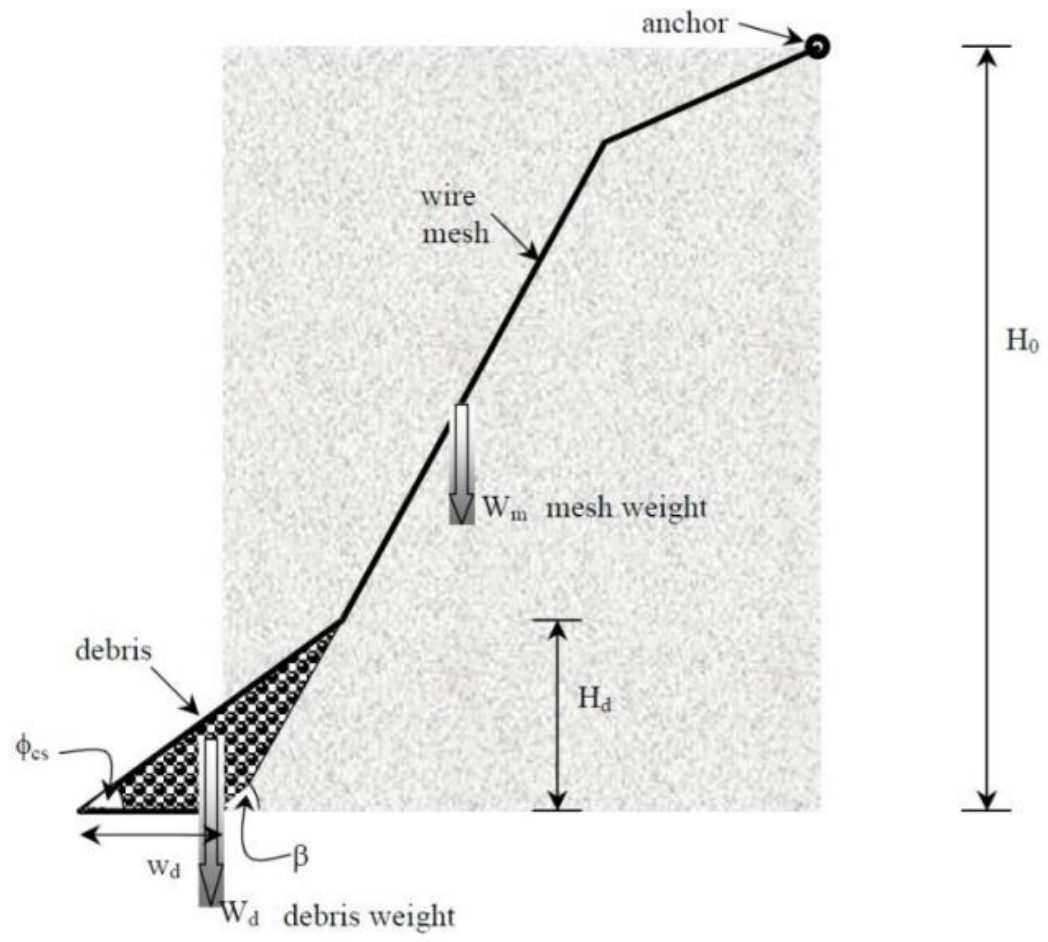

Figure 12 Loads that act on the system (Muhunthan et al. 2005) 
These loads are:

$\mathrm{W}_{\mathrm{d}}=$ load generated by the presence of accumulated debris.

$\mathrm{W}_{\mathrm{S}}=$ load generated by the presence of snow.

$\mathrm{W}_{\mathrm{m}}=$ load generated by mesh panel weight.

According to research undertaken by the U.S. Department of Transportation (Muhunthan et al. 2005), the value of the three components of the stresses and resultant stress on the tail drape are computed as follows:

$$
\begin{gathered}
W_{d}=\frac{1}{2} \cdot \gamma_{d} \cdot H_{d}^{2} \cdot\left(\frac{1}{\tan \Phi_{d}}-\frac{1}{\tan \beta}\right) \cdot \sin (\beta)-\frac{1}{2} \cdot \gamma_{d} \cdot H_{d}^{2} \cdot\left(\frac{1}{\tan \Phi_{d}}-\frac{1}{\tan \beta}\right) \cdot \cos (\beta) \cdot \tan (\delta) \\
W_{s}=\frac{H_{S L O P E}}{\sin (\beta)} \cdot \gamma_{s} \cdot t_{s} \cdot \sin (\beta) \cdot \cos (\beta)-\frac{H_{S L O P E}}{\sin (\beta)} \cdot \gamma_{s} \cdot t_{s} \cdot \cos (\beta) \cdot \cos (\beta) \cdot \tan \left(\varphi_{s}\right) \\
W_{m}=\frac{H_{S L O P E}}{\sin (\beta)} \cdot \gamma_{m} \cdot \sin (\beta)-\frac{H_{S L O P E}}{\sin (\beta)} \cdot \cos (\beta) \cdot \tan (\delta) \\
S=W_{d}+W_{s}+W_{m}
\end{gathered}
$$

where:

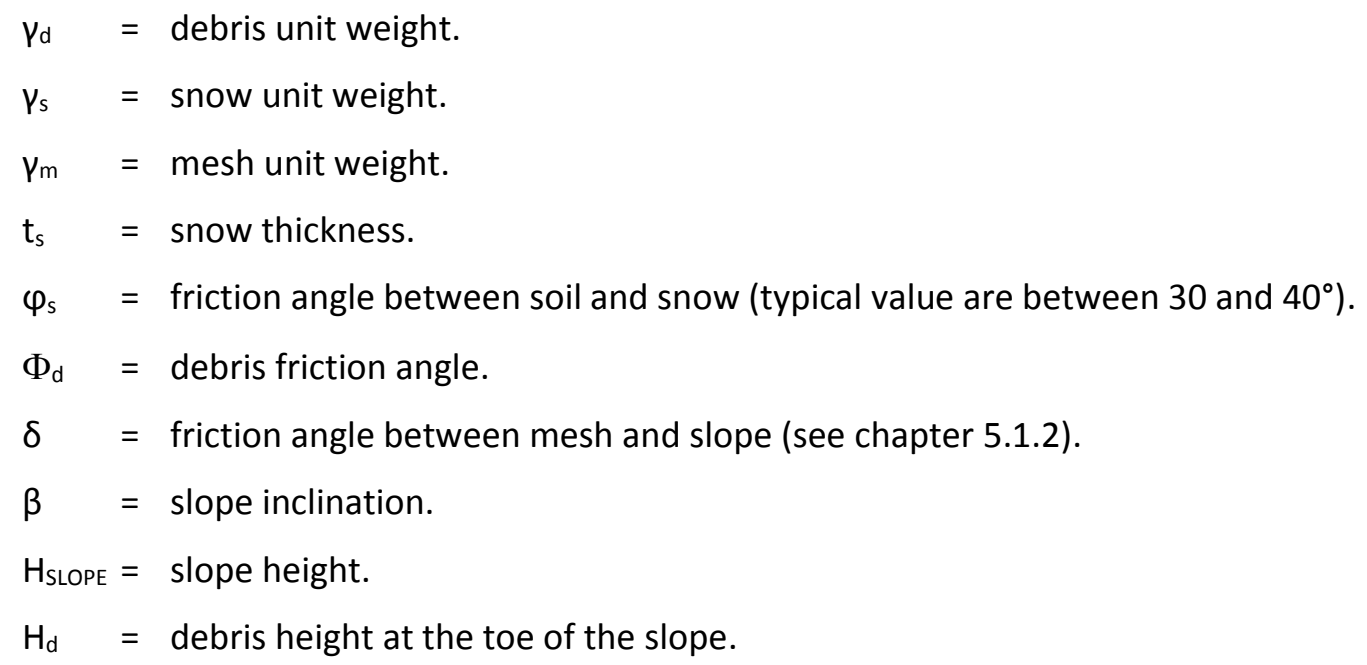

The value of total stress, including security factors $\left(\gamma_{g}\right.$ and $\left.\gamma_{q}\right)$, will be:

$$
S_{W}=\gamma_{q} \cdot W_{d}+\gamma_{q} \cdot W_{s}+\gamma_{g} \cdot W_{m}
$$

where: $\gamma_{q}=$ partial coefficient that increases the snow thickness and the debris accumulation $(\geq 1.0$; suggested value according to the Eurocode 7 (EN 1997) $=1.5)$. And $\gamma_{g}=$ partial coefficient that increases the weight of the mesh ( $\geq 1.0$; suggested value according to the Eurocode 7 (EN 1997) $=1.3$ ).

\subsubsection{Main retention structure static design}

The tensile strength of the main interception structure (ring net, woven rope panel etc.) must withstand the static loads generated by the weight of the mesh, debris and snow (see Section 5.3.1).

The tensile strength of the mesh $\left(R_{m}\right)$ is calculated as:

$$
R_{m}=T_{m} / \gamma_{m t s}
$$

where:

$\mathrm{T}_{\mathrm{m}}=$ ultimate longitudinal tensile strength of the mesh (defined by laboratory tests, i.e. according to UNI 11437:2012), (Figure 13).

$V_{\mathrm{mts}}=$ reduction partial coefficient, which reduces the tensile strength of the mesh ( $\geq 1.0$; from the in situ evidence and laboratory tests, this factor should not be lower than 2.0). 

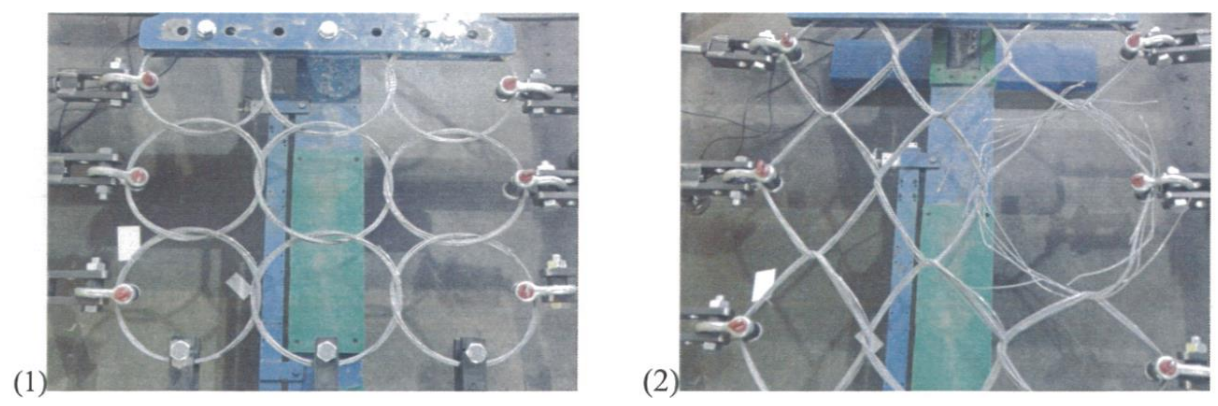

Figure 13 Ring net laboratory test according to UNI 11437:2012

The design is satisfied if:

$$
R_{m}-S_{w} \geq 0
$$

Thus, the safety factor of the mesh, which must be higher than 1 , is equal to:

$$
\mathrm{FS}_{\mathrm{MESH}}=\mathrm{R}_{\mathrm{m}} / \mathrm{S}_{\mathrm{w}} \geq 1
$$

\subsubsection{Transversal longitudinal rope sag design}

This section explains how to calculate the minimum sag required, $\left(f_{\min }\right)$, to avoid the static loads activating the energy dissipater device before the dynamic impact.

The analysis of these forces and geometry (minimum sag of the rope) is delicate. In fact, if the brakes are activated by the static load before the rockfall dynamic impact, the behaviour of the hybrid barrier cannot be compared to the behaviour of a flexible barrier tested, according to ETAG (see Section 5.2).

It is obvious that the designer must know the activation force of the energy dissipater devices $F_{\text {act }}$ (see Figure 14 - bullet on the graph) to complete this calculation. All the manufacturers of flexible barrier have run a large amount of tests on the brakes so the calculation can be performed (see Figure 15).

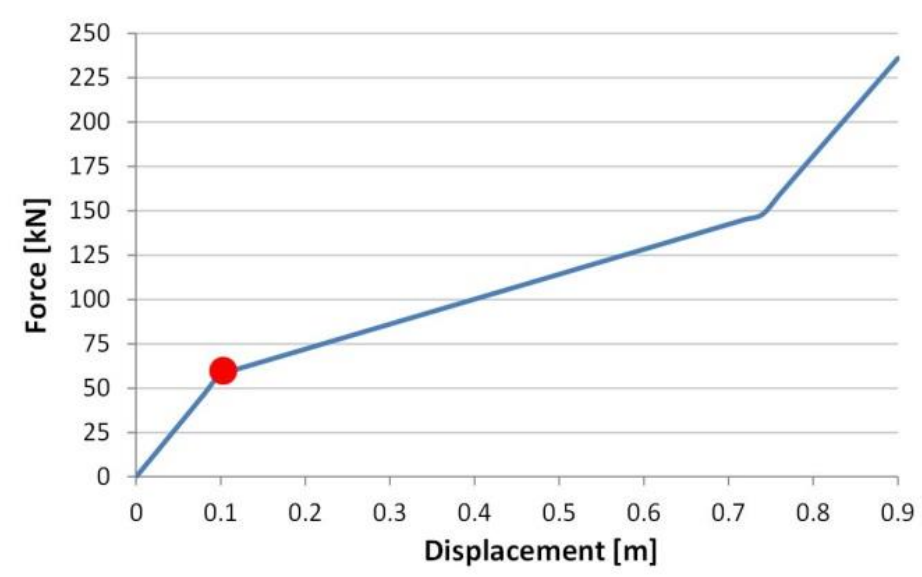

Figure 14 Example of a typical force versus displacement diagram of an energy dissipater device

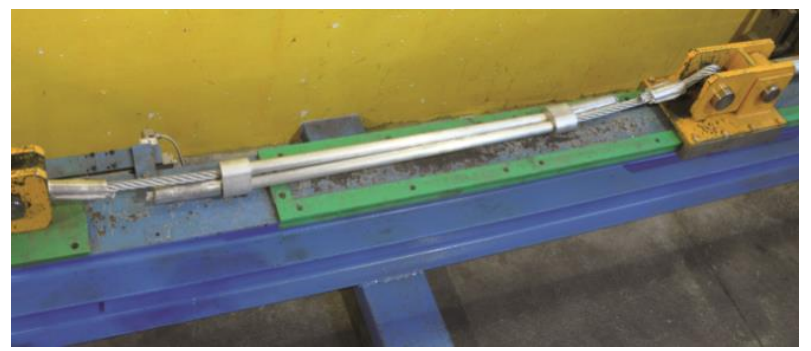

Figure 15 Example of an energy dissipater device (brake) before the test. The deformation of the device absorbs the impact energy 
The draped interception structure is secured on the upper longitudinal cable, which is fixed to the posts (see Section 3). Designers must know the maximum load acting on the drapery (defined in Equation (6)) and the spacing between the posts, in order to calculate the deformation and the stress distribution within the rope. This method uses the principle of the catenary (Figure 16).

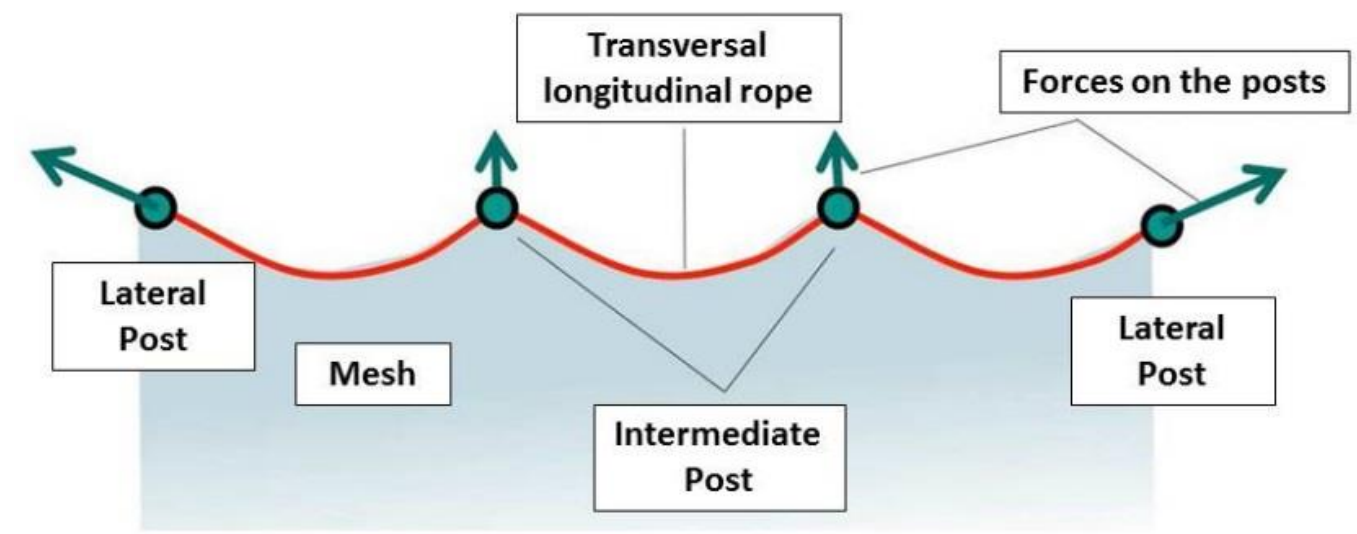

Figure 16 Distribution of the forces on the upper longitudinal cable and crest posts. The cable is considered to form a catenary between posts

Moreover, by using the catenary, it is possible to define the minimum sag required between two consecutive posts to avoid the brakes being activated by the static loads.

According to the scheme of Figure 17, the maximum load $T_{\max }$ acting on the generic rope $i_{\text {th }}$ can be calculated:

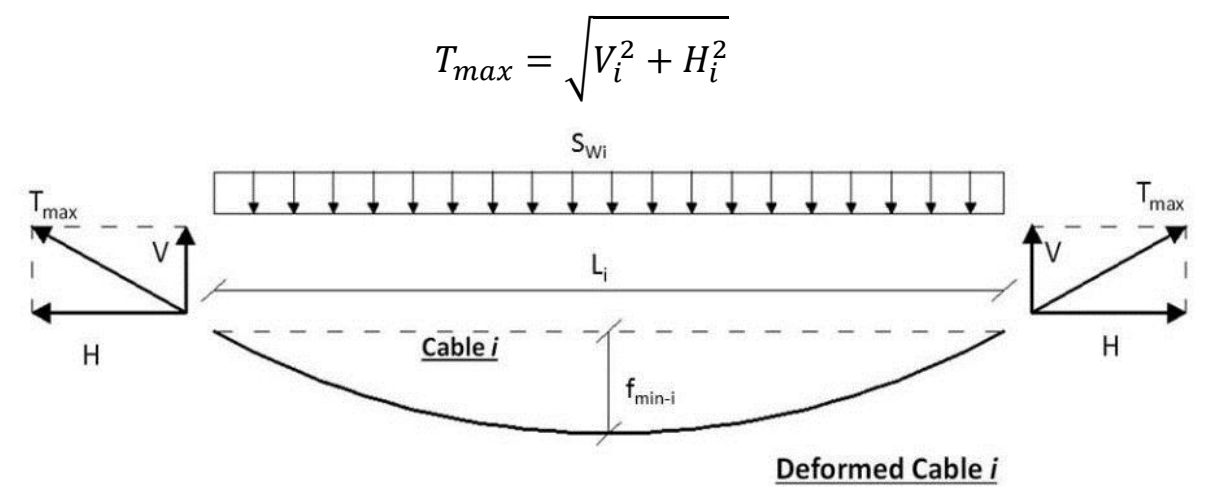

Figure 17 Plan view with the forces acting on the generic deformed rope-ith; $S_{W_{i}}=$ static load acting on the generic rope; $L_{i}=$ width of the generic rope before deforming; $f_{\min }=$ sag of the generic rope

where: $V_{i}$ and $H_{i}$ are the maximum loads acting on the generic rope $i_{\text {th }}$ respectively in the directions parallel and transversal direction (Figure 17). They are defined as the following:

$$
\begin{gathered}
V_{i}=S_{w i} \cdot L_{i} / 2 \\
H_{i}=\left(S_{w i} \cdot L_{i}^{2}\right) /\left(8 \cdot f_{\text {min }-i}\right)
\end{gathered}
$$

The value of $T_{\max }$ depends on $f_{\min }$, which is function of $T_{\max }$. Therefore, an iterative process is needed to solve the problem, but in this particular case it is possible to impose:

$$
\mathrm{T}_{\max }=\mathrm{F}_{\text {act }}
$$

The acting force on the longitudinal upper rope $T_{\max }$ must be, at worst, equal to the activation force, $F_{\text {act, }}$, to avoid the activation of energy dissipater devices. In conclusion, the minimum sag to impose at every longitudinal upper rope at the installation of the barrier has to be equal to:

$$
f_{\text {min }}=\frac{S_{w i} \cdot L_{i}^{2}}{8 \cdot \sqrt{F_{a c t}^{2}-\left(\frac{S_{w i} \cdot L_{i}}{2}\right)^{2}}}
$$




\section{Conclusion}

The goal of this paper is to propose a simplified analytical model to design hybrid barriers, based on the field experiences and research carried out by Arndt et al. (2009), giving designers a tool to select a type of interception structure by considering the impact energy of the rockfall and the morphology of the slope.

Further full-scale tests are required to confirm the complex behaviour of these types of structures. An official, international guideline is also required to help the designer to choose the correct type of hybrid barrier, in every situation.

\section{References}

Arndt, B, Ortiz, T \& Turner, AK 2009, 'Colorado's full-scale field testing of rockfall attenuator systems', Transportation Research Circular E-C141, prepared for the Transportation Research Board, sponsored by the Colorado Department of Transportation (CDOT).

Badger, TC 2007, 'Suspended Draped Rockfall Protection: An Overview of System Performance in Washington', Association of Environmental \& Engineering Geologists - Program with abstracts, p. 68.

Badger, TC, Duffy, JD, Sassudelli, F, Ingraham, PC, Perreault, P, Muhunthan, B, Radhakrishnan, H, Bursi, OS, Molinari, M \& Castelli, E 2008, 'Hybrid Barrier Systems for Rockfall Protection', Workshop on Rockfall Protection, Morschach, Switzerland.

Chai, S, Yacoub, T, Charbonneau, K \& Curran, JJ 2013, 'The effect of rigid body impact mechanics on tangential coefficient of restitution', GeoMontreal 2013, Montreal.

Duffy, JD 2007, 'Hybrid Rockfall Systems', Association of Environmental \& Engineering Geologists — Program with abstracts, p. 80.

EN 1997, 'Eurocode 7: Geotechnical design - Part 1: General rules', European Committee for Standardization (CEN).

EOTA (European Organisation for Technical Approval) 2008, ETAG 027: Guideline for European technical approval of falling rock protection kits, Brussels, www.eota.be

Muhunthan, B, Shu, S, Sashiharan, N, Hattamleh, OA, Badger, TC, Lowell, SL \& Duffy, JD 2005, 'Analysis and Design or Wire Mesh/Cable Net Slope Protection', Washington State Transportation Centre, Seattle, WA-RD 612.1, 267, p. 6.

Smerekanicz, JR, Ingraham, PC, Brandon, PE, Hee, BH, Cajigal, FM \& Journeaux, DL 2008, 'Rock Slope Stabilization Measures at the Pali Tunnel Route 30, Maui, Hawai', 59th Highway Geology Symposium, p. 9.

Sussadelli, F, Perreault, P \& Ingraham, PC 2007, 'Recent rockfall barrier testing in Italy: structural component test and dynamic testing of barrier kits and hybrid barrier/drape system in the framework of European technical guidelines', Program with Abstracts - 50th Annual Meeting of the Association of Environmental and Engineering Geologists, Los Angeles, p. 122.

Tuner, AK \& Schuster, RL 2013, 'Rockfall characterization and control', Transportation Research Board (TRB). 